\title{
The Effect of Myofascial Release Technique and Stretching Versus Myofascial Release Technique and Taping in Patients with Chronic Plantar Fasciitis
}

\author{
Pradeep Krishnareddy ${ }^{1}$, Sharvari Shahane ${ }^{2}$, Yashodhara S Joshi ${ }^{3}$, \\ Vinod Kumar ${ }^{4}$, Sharath $\mathbf{U R}^{5}$ \\ ${ }^{1}$ Principal, Vemana Institute of Physiotherapy, Bangalore- 560034. \\ ${ }^{2}$ Physiotherapist, Bangalore. \\ ${ }^{3}$ Lecturer, Vemana Institute of Physiotherapy, Bangalore- 560034. \\ ${ }^{4}$ Professor, Department of Orthopaedics, Kempegowda Institute of Medical Sciences, Bangalore. \\ ${ }^{5}$ Assistant Professor, Kempegowda Institute of Physiotherapy, K. R. Road, V. V. Puram, Bangalore- 560004.
}

Corresponding Author: Pradeep Krishnareddy

\begin{abstract}
Background and Objective: Plantar fasciitis is the most common cause for inferior heel pain. This study was done to assess the effectiveness of myofascial release technique (MFR) and stretching versus MFR and taping in patients with chronic plantar fasciitis.

Method: 60 plantar fasciitis patients were randomly divided into two groups with $n=30$ in each group. Group 1- received MFR and stretching, where Group 2- received MFR and taping. The treatment was given one session per day for 10 consecutive days for both the groups.

Outcome Measures: The patients were evaluated on day 1, day 5 and day 10 . They were requested to come for a follow up after 1 week of treatment program. All the patients were assessed for pain and foot function by taking their Visual Analog Scale (VAS) and Foot Function Index (FFI).

Results: Group 1 which received MFR and stretching showed great improvements from baseline to week 1, after day 10 on pain intensity and foot function assessed using VAS and FFI respectively. Group 2 showed improvements from baseline to day 10 but there was increase in pain levels and decreased foot function in measurements in 1 week. After analysis group 1 showed significance with $\mathrm{P}=0.001$.

Conclusion: MFR with stretching and MFR with taping both were effective in reducing the pain intensity and increasing the foot function but MFR with stretching showed a superior hand over MFR with taping.
\end{abstract}

Keywords: Plantar Fasciitis, Myofascial Release Technique, Stretching, Taping, Visual Analog Scale, Foot Function Index.

\section{INTRODUCTION}

Plantar fascia is plantar aponeurosis, it lies superficial to the muscles of the plantar surface of the foot. It acts as truss, maintaining the medial longitudinal arch of the foot, and assists during the gait cycle and facilitates shock absorption during weight bearing activities. ${ }^{[1]}$
Plantar fasciitis is another word for the deep fascia of the footpad. It is also referred to as plantar heel pain syndrome, heel spur syndrome or painful heel syndrome. Plantar fasciitis by definition is the inflammation of the plantar fascia. Frequent injury or load to the plantar fascia can cause micro cracks or tears which can 
eventually lead to an inflammation and degeneration of the connective tissue in the fascia. ${ }^{[2]}$ The injury itself is an enthesopathy (an abnormality or injury at the side of attachment of ligament or tendon to the bone) of the origin of plantar fascia at the medial tubercle of the calcaneus. ${ }^{[3]}$

Plantar fasciitis affects adult population. Approximately $10 \%$ of patients with plantar fasciitis have development of persistent and often disabling symptoms. ${ }^{[4]}$ The etiology of this condition is not clearly understood and is probably multifunctional in nature. Obesity, occupation related activity, anatomical variation, poor biomechanics, over exertion and inadequate footwear are contributing factors. ${ }^{[5]}$ The most common cause of injury is overuse such as running; prolong standing, etc., which allow for repetitive micro trauma to the fascia. ${ }^{[6]}$

Plantar fasciitis based on duration of symptoms varies such as acute stage, in which case the symptoms last for fewer than 2 weeks, sub acute stage where symptoms last for 2-6 weeks and chronic stage where symptoms last longer than 6 weeks. ${ }^{[7,8]}$

The classic presentation of plantar fascia is pain on the sole of the foot at the inferior region of the heel. ${ }^{[9]}$ The location of the pain in the heel region can be varied with patients often reporting pain over medial, lateral and lower posterior aspect of the calcaneus. On occasion the patient may also complain of pain over the central band of the plantar fascia in the region of the medial longitudinal arch. ${ }^{[10]}$ Patient reports of pain (throbbing, severe or piercing) to be particularly bad with the first steps taken in the morning or after extended refrain from weight bearing activity but the pain will subside slowly during the next 30-45 minutes, but worsens with continued activity, limiting daily activities of living. There is usually tenderness around the medial calcaneal tuberosity at the plantar aponeurosis. ${ }^{[\boldsymbol{9}, 11]}$ The duration of activity before the onset of heel pain can serve as an excellent indicator of the degree of irritability if the involved tissue. ${ }^{[12]}$
Other characteristic features of plantar fasciitis include tenderness to the anterior medial heel, limited dorsiflexion of the ankle. Many treatment options exist including rest, stretching, strengthening, shoe modification with arch support, anti inflammatory agents and surgery. ${ }^{[5]}$ The treatment aims at reducing pain, inflammation, reducing tissue stress to tolerable level, restoring muscle strength and flexibility of involved tissues. ${ }^{[12]}$

Myofascial release is a soft tissue mobilization technique. It has been considered as one of the physical therapy treatment in the chronic conditions that cause tightness and restriction in the soft tissues like fibromyalgia, post polio syndrome, asymmetrical muscle weakness due to peripheral neuropathy, non flexible rib cage due to chronic respiratory disease and also plantar fasciitis. ${ }^{[13]}$

It was derived from the foundation that fascia, a connective tissue found throughout the body reorganizes itself in response to physical stress and thickness along the lines of tension. ${ }^{[14]}$ By MFR there is change in viscosity of the ground substance to more fluid state which eliminates that fascia's excessive pressure on the pain sensitive structures and restores proper alignment. ${ }^{[15]}$ MFR has been shown to stimulate fibroblast proliferation, leading to collagen synthesis that may promote healing of plantar fasciitis by replacing degenerative tissue with a stronger and more functional tissue. Hence this technique is proposed to act as a catalyst in the resolution of plantar fasciitis. ${ }^{[7,8]}$

Taping technique is also used for the treatment of plantar fasciitis. Taping will help protect the fascia and allow time for healing to occur. The tape should tighten while standing, and should absorb some of the tension that would have been in the fascia (the pain may be relieved immediately). ${ }^{[16]}$ The kinesio tape acts as a form of support without compromising on the patient's range of motion while biomechanically allowing the body to heal itself. ${ }^{[17]}$ 
Stretching is a general term used to describe any therapeutic maneuver designed to increases the extensibility of soft tissues, thereby improving flexibility by elongation of the shortened structures. It plays an important role in treatment of plantar fasciitis and can correct weakness of intrinsic foot muscles. If there is pain with the $1^{\text {st }}$ few steps in morning, massage and stretching the plantar fascia itself before getting out of bed may help. ${ }^{[18,19]}$

There are various studies available proving the individual effect of MFR and stretching technique and taping technique for treating plantar fasciitis. Hence in the present study a comparative analysis was made to find the effectiveness of MFR and stretching versus MFR and taping technique in combination in improving the pain and foot function in patients suffering from chronic plantar fasciitis.

\section{Significance of the study:}

1. The result of the study may help the patients suffering from chronic plantar fasciitis to identify the proper combination of MFR with stretching and MFR with taping.

2. This study can help to identify the duration of reducing the pain and increasing the foot function of patients with chronic plantar fasciitis.

3. The result of the study may also help in establishing the effectiveness of post treatment program relief of pain and improvement of foot function in patients with chronic plantar fasciitis.

4. This study gives an innovative idea for researchers to do further study to analyze various effects of these techniques and maneuvers in improving the patient's condition with chronic plantar fasciitis.

\section{The main objectives of the study were:}

1. To find out the effect of MFR along with stretching in patients with chronic plantar fasciitis.
2. To find out the effect of MFR along with taping in patients with chronic plantar fasciitis.

3. To compare the effectiveness of MFR and stretching over MFR and taping in reducing pain and improving foot function in patients with chronic plantar fasciitis.

\section{MATERIAL AND METHODS}

The study was a hospital centerbased study conducted at the outpatient and inpatient department of orthopedics and physiotherapy in Kempegowda Institute of Medical Sciences, Bangalore.

Study design: randomized study design.

Sample size: 60 (30 subjects in each group)

Sample design: randomized study technique.

criteria:

The following was the inclusion

1. Clinically diagnosed as chronic plantar fasciitis patients.

2. Age group 40-60 years.

3. Patients of both sexes.

And the exclusion criteria were as follows:

1. Subjects with clinical disorders such as infective conditions of foot, tumor, calcaneal fracture, metal implant where MFR is contraindicated.

2. History of systemic disease.

3. Skin disease.

4. History of any major trauma or surgery in and around ankle joint and foot.

5. Subjects with impaired circulation to lower extremity.

6. Subjects with referred pain due to sciatica and other neurological disorders.

7. Foot deformities.

8. Arthritis.

9. Corticosteroid injections in heel preceding 3 months.

10. Subjects using inappropriate footwear.

- Group 1:-

30 subjects in this group were given MFR followed by stretching. Treatment was given for 1 session per day and the total treatment period was for 2 weeks. 
For MFR, the patients were asked to lie down prone on a couch with their feet out of the couch. They were given a pillow under their feet for support and comfort. The area of treatment was cleaned and dried. The therapist evaluated the area of treatment. The therapist was standing near the foot end of the patient. Sustained gentle pressure in the line with the fibers of plantar fascia from calcaneus towards the toes, using the thumb was given. ${ }^{[20]}$ This pressure was held for 90 seconds. This MFR was given for 15 minutes per session with $1 \mathrm{~min}$ of rest interval. For 5 days per week. The total treatment period was for 2 weeks.

Stretching technique followed this. The stretching was given specific for plantar fascia. For the stretching technique, the patients were asked to lie supine. They were given a pillow under their feet for comfort. The therapist supported the affected side ankle with 1 hand. With the other hand, the therapist gives stretch to the plantar fascia. For this the foot is kept in neutral position. The therapist places his fingers on the patient's toes and extends them till the patient feels the stretch on the plantar fascia. The stretch is checked by palpating tension over plantar fascia. ${ }^{[4]}$ This stretch was held for 30 seconds with 15 seconds rest time between each stretch. 6 repetitions of the plantar stretch were given for 5 sessions per week. ${ }^{[21]}$ The total treatment period was for 2 weeks.

\section{- Group 2:-}

30 subjects in this group were given MFR followed by taping. Treatment was given for 1 session per day and the total treatment period was for 2 weeks.

For MFR, the protocol was same as mentioned for Group 1.

After MFR was given to the patients, calcaneal taping was done for them. For the calcaneal taping the patients were asked to lie prone with their feet resting slightly outside the couch on a pillow for comfort. The affected foot was kept in neutral position. One end of the tape was fixed to the patient's calcaneus from posteriorly and pulled towards toes from the plantar surface, with slight tension on the tape. Again a second tape is put in a figure of eight around the patient's ankle with slight tension on the tape. Taping was done once per session. 5 sessions per week were done. The total treatment period was for 2 weeks. ${ }^{[22,23]}$

The subjects in both the groups were advised not to stand and not to run for a long time and not to walk bare foot. Also the subjects were advised not to indulge in any other treatment for their plantar fasciitis.

Baseline measurements of pain intensity and foot function were assessed using VAS and FFI, again pre treatment measurements were taken on day 5, day 10 . The patients were requested to come back for follow up measurements after 1 week of the end of treatment program.

\section{STATISTICAL ANALYSIS: \\ Repeated measure of Analysis of Variance (r ANOVA):}

One of the most common approaches to experimental design is to compare two or more groups with the intent of seeing if they significantly differ from each other. Typically this independence is achieved by measures such as beginning with a heterogeneous sample and randomly allocating that sample into various test conditions. While such an approach works it is not always possible or desirable to have all groups fully independent. In the study like the present one, on every patient four measurements are to be made on day 1 , day 5 , day 10 and 1 week after. These types of measurements are called repeated measures. Here the performance of the patient what it was on Day 1 influences performance on day 5 and day 10 because of the therapy given between these time points. Similarly, the performance of day 10 influences on 1 Week due to the therapy and hence creates repeated measures, which are dependent observations. For this type of repeated measures, a statistical test applied to find out the significant improvement from Day 1 to 1 Week after day 10 is repeated measure 
of Analysis of Variance ( $\mathrm{r}$ ANOVA). It is used to measure the improvement or effectiveness of treatment/ therapy. It is called repeated measure because on every subject the measurements are made more than two times at different time points. Like in Analysis of Variance, in repeated Analysis of variance also some assumptions are to be fulfilled to apply it analyzing the data. One of the most important assumptions is to verify for sphericity (testing equality of variances) from one observation to another. Testing for sphericity is done using Mauchly's Chisquare test. If this test shows significant result, that is, $\mathrm{P} \leq 0.05$ shows that the variances are not equal. In such cases the ANOVA is carried out by correcting the degrees of freedom using GreenhouseGeisser method for appropriateness, the testing for equality of means from Day 1 through different readings to 1 Week. ${ }^{[24,25]}$

Statistical software: The statistical software namely SPSS 16.0 was used for the analysis of the data and Microsoft Word and Excel have been used to generate graphs, tables, etc.

\section{RESULTS}

Table no. 1: Sex distribution of subjects according to age groups.

\begin{tabular}{|l|l|l|l|}
\hline Age (years) & Male & Female & Total \\
\hline$\leq 40$ & 1 & 1 & 2 \\
\hline $41-50$ & 14 & 13 & 27 \\
\hline $51-60$ & 15 & 16 & 31 \\
\hline Total & 30 & 30 & 60 \\
\hline
\end{tabular}

In table no. 1, 60 subjects of chronic plantar fasciitis with an age between 40-60 years were selected for this study. The number of males and females according to age groups of less than or equal to 40, 41-50 and 50-60 are given in the table.

Table no. 2: Assessment of pain intensity using VAS for group 1.

\begin{tabular}{|c|c|c|c|c|c|c|}
\hline Pain intensity score using VAS for Group 1 & Mean & SD & Mauchly's Chi-square value & P-value & $\begin{array}{l}\text { Greenhouse- } \\
\text { Geisser F-value }\end{array}$ & $P$-value \\
\hline Base line & 7.30 & 0.88 & \multirow{4}{*}{17.006} & \multirow{4}{*}{0.001} & \multirow{4}{*}{501.013} & \multirow{4}{*}{0.001} \\
\hline Day 5 & 5.33 & 1.06 & & & & \\
\hline Day 10 & 3.27 & 1.17 & & & & \\
\hline 1 week & 2.37 & 1.00 & & & & \\
\hline
\end{tabular}

In table no. 2 the pain intensity score using VAS for group 1 is given. The VAS score was taken as baseline, day 5, day 10 , and 1 week after the treatment as a follow up. The table gives the mean $\pm \mathrm{SD}$ of the VAS score on all these days. The mean \pm SD scores on baseline were $7.30 \pm 0.88$ as compared to $2.37 \pm 1.0$ on week 1 . The scores assessed on patients' in-group 1 for pain intensity using VAS had a significant effect $(\mathrm{F}=501.013, \mathrm{P}<0.001)$.

Table no. 3 assessed the foot function on baseline, day 5, day 10, and 1 week after. The mean \pm SD on baseline was $77.43 \pm 7.06$ as compared to $37.73 \pm 9.28$ on 1 week. The scores assessed on patients for foot function had a significant effect $(\mathrm{F}=500.539, \mathrm{P}=0.001)$.

Table no. 3: Assessment of foot function using FFI for group 1.

\begin{tabular}{|c|c|c|c|c|c|c|}
\hline $\begin{array}{l}\text { Foot function using foot function index } \\
\text { for Group } 1\end{array}$ & Mean & SD & Mauchly's Chi-square value & P-value & $\begin{array}{l}\text { Greenhouse- } \\
\text { Geisser F-value }\end{array}$ & P-value \\
\hline Base line & 77.43 & 7.06 & \multirow{4}{*}{53.019} & \multirow{4}{*}{0.001} & \multirow{4}{*}{500.539} & \multirow{4}{*}{0.001} \\
\hline Day 5 & 57.47 & 7.11 & & & & \\
\hline Day 10 & 40.10 & 9.99 & & & & \\
\hline 1 week & 37.73 & 9.28 & & & & \\
\hline
\end{tabular}

Table no. 4: Assessment of pain intensity using VAS for group 2.

\begin{tabular}{|c|c|c|c|c|c|c|}
\hline $\begin{array}{l}\text { Pain intensity score using VAS for Group } \\
2\end{array}$ & Mean & SD & Mauchly's Chi-square value & P-value & $\begin{array}{l}\text { Shericity } \\
\text { assumed }\end{array}$ & $\begin{array}{l}\text { P- } \\
\text { value }\end{array}$ \\
\hline Base line & 7.33 & 0.84 & \multirow{4}{*}{6.844} & \multirow{4}{*}{0.233} & \multirow{4}{*}{158.935} & \multirow{4}{*}{0.001} \\
\hline Day 5 & 5.83 & 0.99 & & & & \\
\hline Day 10 & 4.47 & 1.17 & & & & \\
\hline 1 week & 5.33 & 0.99 & & & & \\
\hline
\end{tabular}

In table no. 4 the pain intensity score using VAS for group 2 is given. The VAS score was taken as baseline, day 5 , day 10 , and 1 week after the treatment as a follow 
up. The table gives the mean $\pm \mathrm{SD}$ of the VAS score on all these days. The mean \pm SD scores on baseline were $7.33 \pm 0.84$ as compared to $5.33 \pm 0.99$ on week 1 . The scores assessed on patients' in-group 1 for pain intensity using VAS had a significant effect $(\mathrm{F}=158.935, \mathrm{P}<0.001)$.

Table no. 5: Assessment of foot function using FFI for group 2.

\begin{tabular}{|c|c|c|c|c|c|c|}
\hline $\begin{array}{l}\text { Foot function using foot function index } \\
\text { for Group } 2\end{array}$ & Mean & SD & Mauchly's Chi-square value & P-value & $\begin{array}{l}\text { Greenhouse- } \\
\text { Geisser F-value }\end{array}$ & P-value \\
\hline Base line & 78.97 & 7.32 & \multirow{4}{*}{66.318} & \multirow{4}{*}{0.001} & \multirow{4}{*}{309.249} & \multirow{4}{*}{0.001} \\
\hline Day 5 & 64.90 & 10.05 & & & & \\
\hline Day 10 & 51.50 & 10.94 & & & & \\
\hline 1 week & 55.20 & 10.45 & & & & \\
\hline
\end{tabular}

Table no. 5 assessed the foot function on baseline, day 5, day 10, and 1 week after. The mean $\pm \mathrm{SD}$ on baseline was $78.97 \pm 7.32$ as compared to $55.20 \pm 10.45$ on 1 week. The scores assessed on patients for foot function had a significant effect assessed using Greenhouse- Geisser technique $(\mathrm{F}=309.249, \mathrm{P}=0.001)$.

Table no. 6: Comparison of VAS scores in group 1 and group 2.

\begin{tabular}{|l|l|l|l|l|l|l|}
\hline \multirow{2}{*}{ Pain intensity score using VAS } & \multicolumn{2}{|l|}{ Group 1 } & \multicolumn{2}{|c|}{ Group 2 } & \multirow{2}{*}{ t-value } & \multirow{2}{*}{ P-value } \\
\cline { 2 - 6 } & Mean & SD & Mean & SD & & \\
\hline Base line & 7.30 & 0.88 & 7.33 & 0.84 & 0.15 & 0.88 \\
\hline Day 5 & 5.33 & 1.06 & 5.83 & 0.99 & 1.89 & 0.06 \\
\hline Day 10 & 3.27 & 1.17 & 4.47 & 1.17 & 3.97 & 0.00 \\
\hline 1 week & 2.37 & 1.00 & 5.33 & 0.99 & 11.53 & 0.00 \\
\hline
\end{tabular}

Table no. 6 show comparison of VAS in group 1 and group 2. From baseline to 1 week the mean \pm SD of both the groups is given. Group 1 shows marked improvements in pain intensity. The values of VAS have dropped from baseline to day 10. Even the follow up measurements show reduction in pain intensity. Whereas ingroup 2, pain levels show reduction from baseline to day 10. But in the follow up measurement there is increase in the pain values. The scores assessed for both the groups for pain intensity using VAS shows significance $(\mathrm{P}=0.00)$

Table no. 7: Comparison of foot function index scores in group 1 and group 2.

\begin{tabular}{|l|l|l|l|l|l|l|}
\hline \multirow{2}{*}{ Foot function using foot function index } & \multicolumn{2}{|c|}{ Group 1 } & \multicolumn{2}{|c|}{ Group 2 } & \multirow{2}{*}{ t-value } & \multirow{2}{*}{ P-value } \\
\cline { 2 - 6 } & Mean & SD & Mean & SD & & \\
\hline Base line & 77.43 & 7.06 & 78.97 & 7.32 & 0.83 & 0.41 \\
\hline Day 5 & 57.47 & 7.11 & 64.90 & 10.05 & 3.31 & 0.00 \\
\hline Day 10 & 40.10 & 9.99 & 51.50 & 10.94 & 4.21 & 0.00 \\
\hline 1 week & 37.73 & 9.28 & 55.20 & 10.45 & 6.84 & 0.00 \\
\hline
\end{tabular}

Table no. 7 gives mean \pm SD values of foot function index comparison between both the groups from baseline to 1 week. The foot function index also shows improvement from baseline to 1 week ingroup 1, whereas in group 2 it shows improvement from baseline to day 10 . There is increase in values from day 10 to 1 week after. The scores assessed for foot function using FFI show significance $(\mathrm{P}=0.00)$

\section{Interpretations of results:}

In this study 60 subjects who had chronic plantar fasciitis and who fell in the inclusion criteria were selected. They were allotted randomly in two groups, group 1 and group 2 consisting of 30 subjects each. To compare the effectiveness of MFR and stretching over MFR and taping in reduction of pain intensity by VAS and improvement in foot function by using foot function index was the objective.

The data were analyzed using repeated measures of ANOVA test to find the significance of the interventions used within the groups and then Mauchly's Chisquare test was used for the abovementioned parameter to find the significance between the groups. The analytical test showed significance for both the groups stating MFR and stretching and MFR and taping were both effective in 
reducing the pain intensity and increasing the foot function within the groups. The group 1 showed improvements from baseline till 1 week after day 10 measurements and showed more significance than group 2 which showed improvements from baseline to day 10 but showed slight increase in pain intensity and reduced foot function in 1 week measurements after day 10. Hence, group 1 showed more significance than group 2 .

The results were found to be significant at $\mathrm{P}<0.05$ with calculated ' $\mathrm{t}$ ' values as 11.53 and 6.84 for pain intensity and foot function respectively, stating that there is a significant effect using MFR and stretching for patients suffering with chronic plantar fasciitis in group 1 compared to patients of group 2 treated with MFR and taping in reducing pain intensity and improving foot function.

\section{DISCUSSION}

The chief objective of this study was to compare the efficacy of MFR and stretching over MFR and taping in patients with chronic planter fasciitis in reducing the pain intensity and improving the foot function assessed by VAS and FFI respectively. The study was detailed and tailored to find which mode of treatment was better in the two groups after 10 days of treatment and 1 week follow up after 10 days treatment.

Pre treatment values of pain intensity using VAS and foot function using FFI on baseline, day 5, day 10 and 1 week after day 10 were assessed. These values were statistically analyzed using repeated measures of ANOVA test and Mauchly's Chi- square test. The statistical analysis done for both the groups showed reduction in pain intensity and improvements in foot function.

It also showed that subjects from group 1 showed more improvements in foot function and pain reduction from baseline to day 10 of treatment and maintained the improvements till after 1 week of day 10 . Whereas subjects from group 2 showed improvements from baseline to day 10 till the treatment was given to them but showed mild increase in pain and reduced foot function after the treatment was stopped. They showed increased pain levels and reduced foot function compared to day 10 and 1week measurements. Hence, group 1 treated with MFR and stretching showed higher significance than group 2 treated with MFR and taping. Based on this data we accept the alternate hypothesis and reject the null hypothesis.

These results were significant at $\mathrm{P}=0.00$ and it strongly supports the earlier findings of SUMAN KUHAR (2007) who took 30 subjects and separated them into 2 groups. One group received therapeutic ultrasound and contrast bath for 20 minutes with foot intrinsic muscles strengthening exercises and plantar fascia stretching exercises and other group received conventional treatment. The outcome was assessed in terms of foot function index and visual analog scale. It concluded that MFR is an effective therapeutic option in treatment of plantar fasciitis. ${ }^{[20]}$

The results of this study also has got strong evidences from the study done by BARNES JF (1990) who said that myofascial release technique is based in the idea that poor posture physical injury, illness and emotional stress can cause the fascia to become fat and constricted throughout the body (fascia links every organ and tissue in the body with every other part); the skillful and dexterous use of hands is said to free up or release disruptions in these fascial network. Pressure on the bones, muscles, joints and nerves is released in the process and balance is restored. ${ }^{[14]}$

This study implies that both MFR and stretching and MFR and taping can be used for treating chronic plantar fasciitis patients but for long term effectiveness of the treatment the former is more efficient than the later. 


\section{Limitations of the study:}

- The study was limited to age group of 40-60 years.

- The study was limited to chronic planter fasciitis patients.

- The study was limited to assess only the pain intensity by using VAS and foot function by using FFI.

- The study had a short duration follow up of only 1 week post treatment.

\section{Suggestions and further recommendation:}

- As this study was done only with chronic plantar fasciitis, further studies are also suggested to detect the progress in patients with other foot problems.

- In this study, subjects were tested for pain and foot function, similar studies could also be done to detect the strength of intrinsic foot muscles.

- Further studies should be conducted in larger sample size and with wider age group as this study only considered age group from 40-60 years.

- This study could be done with control group for whom intervention will not be given so that there will be a chance to know the outcome of myofascial release technique and stretching alone in more significant manner.

- As this study was done only for a short period, a long term study should be conducted with long term follow up sessions to know the effectiveness of the treatment.

\section{CONCLUSION}

This study can be concluded by stating that both MFR and stretching and MFR and taping have got beneficial effect in reducing the pain intensity and improving the foot function in patients with chronic plantar fasciitis.

Both the treatments showed significance in reducing the pain levels and improving the foot function from baseline to day 10 of treatment. But only subjects in Group 1 showed improvements in measurements taken in the follow up 1 week after day 10. Group 2 subjects came back with mild increase in pain levels and reduced foot function in the follow up measurements.

When both the treatment regimens were taken into consideration for significance, the MFR and stretching, MFR and taping showed effectiveness in reducing the pain intensity and increasing the foot function but MFR and stretching showed superior hand over MFR and taping.

\section{Acknowledgement: None}

Conflict of Interest: None

\section{Source of Funding: None}

\section{Ethical Approval: Approved}

\section{REFERENCES}

1. Simon J. Bartold. Plantar heel pain syndrome: overview and management. Journal of bodywork and movement therapies 2004;214-226

2. Daniel L., Riddle et al. Risk factors for plantar fasciitis: A matched casecontrol study. The Journal of Bone and Joint Surgery(American) 2003; 85: 872-77

3. Robert Donatelli, Steven L Wolf. The biomechanics of the foot and ankle. F A Davis, Philedelphia 1990;141-156

4. Benedict F., Digivonni et al. Tissue Specific plantar fascia stretching exercise enhances outcomes in patients with chronic heel pain. The Journal of Bone and Joint Surgery 2003

5. Pfeffer $G$, Baccheti $P$, Deland $J$ et al. Comparison of custom and prefabricated orthoses in the initial treatment of proximal plantar fasciitis. Foot Ankle Int. 1999 Apr;20(4):214-21. doi: 10.1177/ 107110079902000402.

6. Young B, Walker MJ et al. A combined treatment approach emphasizing impairment based manual physical therapy for plantar heel pain: a case series. JOSPT 2004; 34:725-33

7. Richard MD, Sherwood SM, Sculties S, Knight. Effects of tape and exercise on dynamic ankle incersion. Phys Sports Med 2000 Jan;35(1):31-37

8. Furey JG. Effects of myofascial release on plantar fasciitis. J Bone Surg 1978;57:67273 
9. Mario Roxas, ND. Plantar Fasciitis: Diagnosis and Therapeutic considerations. Alternative Medicine Review 2005; 10(2): 83-93

10. Crawford F, Atkins D, Edwards J. Intervention for treating plantar heel pain, Foot 2002;11:228-250

11. Amis J, Jennings L, Graham D, Graham CE. Painful heel syndrome: radiography and treatment assessment. Foot ankle 1988;9:9195

12. Cornwall M, McPoil T. Plantar fasciitisetiology and treatment. J Orhto Sports Phys Ther 1999;29(12):756-60

13. Schepsis AA, Leach RE, Gorzyca J. Plantar fasciitis- etiology, treatment, surgical results and review of literature. Clin Orthop 1991;266:185-96

14. Barnes JF. Myofascial release- the search of excellence rehabilitation service. PA medicine 1990;25:721-25

15. Travell J., Simons, Myofascial pain and dysfunction, The trigger point manual vol 1 . Williams and Wilkins, Baltimore 1992

16. Shea M, Fields KB. Plantar fasciitis- effects of tape and exercise. Phys Sports Med 2002;30(7)

17. Halseth T, McChesney JW et al. The effects of kinesio taping on proprioception at the ankle. Journal of Sports Sciences and Medicine 2004;3:1-7

18. Daniel. Rehabilitating Plantar Fasciitis 2007

19. Powell M, Post WR, Kenerj, Wearden S. Effective treatment of chronic plantar fasciitis with dorsiflexion night splint; a cross over prospective randomized outcome study. Foot ankle 1998;19:10-80

20. Suman Kuhar. Effectiveness of myofascial release in treatment of plantar fasciitis. Indian Journal of Physical Therapy and Occupational Therapy 2007 julysept;1(3):221-25

21. Kisner Carolyn and Colby. Therapeutic exercise foundation and technique. $4^{\text {th }} \mathrm{Ed}$. Jaypee Brother's publication 2002;330-345

22. Hyland MR, Webber Gaffney A, Cothen, Lichtampi. Randomized controlled trial of calcaneal taping, sham taping and plantar fascia stretching for short term management of plantar heel pain. Clinical Sports Medicine 2006 june;36(6):364-71

23. Jam B, Varamini A. A clinical manual therapeutic taping $1^{\text {st }}$ Ed. 2004

24. Carolyn M Hicks. Research methods for clinical therapists $3^{\text {rd }}$ Ed. Churchill Livingstone 1999;131-209

25. CR Kothari. Research Methodology methods and techniques $2^{\text {nd }}$ Ed. New age international publications 2005;31-35

How to cite this article: Krishnareddy P, Shahane S, Joshi YS et.al. The effect of myofascial release technique and stretching versus myofascial release technique and taping in patients with chronic plantar fasciitis. Int $J$ Health Sci Res. 2021; 11(9): 1-9. DOI: https://doi.org/10.52403/ijhsr.20210901 